\title{
Anomalous Upwelling in Nan Wan: July 2008
}

\author{
Dong Shan $\mathrm{Ko}^{1, *}$, Shenn-Yu Chao ${ }^{2}$, Phillip Huang ${ }^{3}$, and Sheng Fong Lin ${ }^{4}$ \\ ${ }^{1}$ Naval Research Laboratory, Stennis Space Center, Mississippi 39529, USA \\ ${ }^{2}$ Horn Point Laboratory, University of Maryland Center for Environmental Science, Cambridge, Maryland 21613, USA \\ ${ }^{3}$ Seawatch Co., 103 Dalong Street, Taipei 10366, Taiwan, ROC \\ ${ }^{4}$ University of New Orleans, Stennis Space Center, Mississippi 39529, USA
}

Received 6 August 2008, accepted 25 November 2008

\begin{abstract}
Tidally induced, sudden temperature drops in Nan Wan, particularly pronounced during the spring tide, often bear ecological consequences. We use an Ocean Nowcast/Forecast System (ONFS) at the US Naval Research Laboratory (NRL) to examine a widely publicized cold-water intrusion event in July 2008, and compare it with what we perceived as a normal intrusion event in June 2007. For a normal cold-water intrusion, cold anomalies eventually propagate away in forms similar to internal Kelvin waves. For early July of 2008, the NRL ONFS suggested an anomalous, subtidal and essentially eastward current near Nan Wan. The subtidal current, superimposed on the ebb current, blocks the propagation of cold anomalies in the direction of internal Kelvin waves, inducing anomalous and inefficient cold-water dispersal. The NRL ONFS also suggested the anomalous subtidal current as a post-typhoon response to the passage of Typhoon Fengshen.
\end{abstract}

Key words: Nan Wan upwelling, Tide-induced upwelling, Cold-water intrusion, Typhoon-Ocean interaction Citation: Ko, D. S., S. Y. Chao, P. Huang, and S. F. Lin, 2009: Anomalous upwelling in Nan Wan: July 2008. Terr. Atmos. Ocean. Sci., 20, 839-852, doi: 10.3319/TAO.2008.11.25.01(Oc)

\section{INTRODUCTION}

Nan Wan, or the south bay of Taiwan, is a semi-enclosed basin open to the Luzon Strait (Fig. 1). The northward flowing Kuroshio follows the western extreme of the Philippine Sea from the east coast of Luzon to the east coast of Taiwan. In summer, the Luzon Strait is more or less free from $\mathrm{Ku}-$ roshio encroachment and, in consequence, the Kuroshio often stays some distance away from Nan Wan and its vicinity. In winter, the encroaching Kuroshio often enters the northern South China Sea, looping anticyclonically before exiting the South China Sea along the southern tip of Taiwan (e.g., Centurioni et al. 2004; Wu and Chiang 2007; Liang et al. 2008). Conceivably, the encroachment breeds eddy shedding and moves the Kuroshio much closer to Nan Wan and its vicinity.

Tidal currents to the south of Nan Wan are essentially eastward during ebb and westward during flood. Subtidal currents, especially those related to the Kuroshio, could conceivably modify the strength of the flood and ebb currents. Diurnal tides are, more often than not, stronger than semi-

\footnotetext{
* Corresponding author

E-mail:ko@nrlssc.navy.mil
}

diurnal tides in the Luzon Strait and Nan Wan. The anomalous amplification of diurnal tides over semidiurnal tides is due to the basin-wide resonance that involves the entire basin of the South China Sea (Jan et al. 2007). In Nan Wan and its vicinity, the diurnal tide, modulated by a semidiurnal beat, often induces upwelling or cold-water intrusion that occurs daily (Lee et al. 1997). The upwelling is particularly strong and widespread during the spring tide (Chen et al. 2004). On the east side of Nan Wan, the temperature drop lasts for a few hours each and usually occurs once every diurnal tidal cycle. In west and central parts of the basin, similar temperature drop usually occurs twice in one diurnal tidal cycle (Lee et al. 1999). The temperature drop could be sudden and drastic. On 24 November 1988, for example, a sudden temperature drop of more than $10^{\circ} \mathrm{C}$ resulted in a mass kill of fish (Su et al. 1989).

Theoretically, both capes (Mou-Bi-Tou and O-Luan-Bi in Fig. 1b) and their southward extension ridges are capable of producing upwelling. A ridge induces upwelling by lifting the incoming tidal current. A cape can achieve a similar effect. It blocks the incoming tidal current, which needs to detour around the cape to supply waters to the lee side. The 
inefficiency of water supply creates a relatively low sea level anomaly in the lee and bottom waters normally upwell to fill the void. This is, in essence, the conclusion from the previous numerical model (Lee et al. 1999). Given the complex tidal constituents, bathymetry and coastline orientation in and around Nan Wan, it is difficult to assess the importance of each cape and ridge in producing upwelling without realistic numerical simulations.

In the afternoon of 3 July 2008 local time (early morning of July 3 in GMT), fishermen spotted a large school of fish floating in the western reaches of Nan Wan. The collective diagnosis afterwards pointed to hypothermia as the likely cause. A bottom temperature sensor at station $\mathrm{T}$ lent further support to this idea. The event motivated us to investigate further using an Ocean Nowcast/Forecast System (ONFS) of the US Naval Research Laboratory (NRL) (Ko et al. 2008). Not surprisingly, the NRL ONFS identified this period as a spring tide that generated strong upwelling in Nan Wan. When comparing the July 2008 upwelling event with previous ones, we also identified two types of pathways for the dispersal of cold anomalies: one disperses in the propagation direction of internal Kelvin waves and the other in the opposite direction. In the formal case or normal upwelling event, cold anomalies seem to disperse easily and do not overaccumulate in Nan Wan. In the latter case or anomalous upwelling event, the dispersion seems slow and the temperature drop in Nan Wan becomes more severe. For the particular cold event in July 2008, the NRL ONFS suggests that typhoon Fengshen in the preceding month created the preconditioning for the anomalous upwelling.

\section{OCEAN NOWCAST/FORECAST SYSTEM}

We use a real-time Ocean Nowcast/Forecast System developed at the US Naval Research Laboratory to facilitate the present study. The NRL ONFS produces a daily, short-term (under a week) forecast of: mesoscale ocean currents, temperature, salinity, and sea level variation. The system can be relocated to different regions and, once set up for a particular region, operates automatically. The system is an integration of: a data-assimilating, dynamical ocean model, a statistical data-analysis model, and various data streams for ocean bathymetry, climatological data, surface forcing, open boundary forcing, and observations for data assimilation (Ko et al. 2008). The NRL Modular Ocean Data Assimilation System (MODAS; Carnes et al. 1996; Fox et al. 2002) is used within ONFS as the data-analysis model. MODAS uses satellite data, in-situ observations and historical statistics to generate three-dimensional ocean temperature and salinity analyses. The analyses are then assimilated into the dynamic model to produce an ocean nowcast. From the nowcast, the forecast is conducted without data assimilation using a meteorological forecast. This paper only uses the nowcast portion of the results for analysis.
This paper primarily uses results from a high resolution Luzon Strait Nowcast/Forecast System (LZSNFS), an application of NRL ONFS, to discuss upwelling in and around Nan Wan. The system domain extends from $116^{\circ} \mathrm{E}$ to $125^{\circ} \mathrm{E}$ and from $17^{\circ} \mathrm{N}$ to $24^{\circ} \mathrm{N}$, covering the northern South China Sea, the Luzon Strait, and a portion of the Philippine Sea with a horizontal resolution of $2.3 \mathrm{~km}$. In terms of vertical resolution, there are $11 \sigma$-layers in the top $147 \mathrm{~m}$ and 29 z-layers below. The system derives its ocean bottom topography from the Digital Bathymetry Data Base with 2minute resolution (DBDB2). Open boundary conditions are derived from a larger scale ONFS for the entire East Asian Seas (EASNFS). The Oregon State University (OSU) tidal forcing drives the tidal currents. A global weather forecast model (Navy Operational Global Atmospheric Prediction System or NOGAPS) and a regional weather forecast model (Coupled Ocean/Atmosphere Mesoscale Prediction System or COAMPS) provide the ocean surface forcing. The LZSNFS also assimilates satellite altimeter data and MultiChannel Sea Surface Temperature (MCSST) from satellitederived AVHRR to improve accuracy further.

The system is able to produce rather accurate tidal current in the Luzon Strait and northern South China Sea. For example, tidal currents flowing over the ridges in the Luzon Strait generate large-amplitude nonlinear internal waves in the northern South China Sea, vividly seen in satellite images. To reproduce the timing and location of these internal waves requires accurate spatial and temporal distribution of tidal currents and LZSNFS was able to achieve this (Chao et al. 2007).

In addition to LZSNFS, we also use results from the larger scale EASNFS, another application of NRL ONFS, to diagnose the origin of anomalous Nan Wan upwelling in July 2008. The EASNFS covers the western Pacific and all the Asian marginal seas from $17.3^{\circ} \mathrm{S}$ to $52.2^{\circ} \mathrm{N}$ and from $99.2^{\circ} \mathrm{E}$ to $158.2^{\circ} \mathrm{E}$ with a resolution of $1 / 16$ degree or $9.2 \mathrm{~km}$ at latitude of Luzon Strait. The system derives its open ocean boundary conditions from NRL global NCOM (Navy Coastal Ocean Model) (Rhodes et al. 2002) that operates daily. Contrary to fine-scale LZSNFS, the EASNFS does not simulate tides. The vertical resolution, forcing and methodology of EASNFS are otherwise similar to that in LZSNFS. The EASNFS has been applied for studies of current at Korea/Tsushima Strait (Teague et al. 2006), transport in the Gulf of Papua (Keen et al. 2006), typhoon-ocean interaction at the West Pacific Ocean (Lin et al. 2008) and air-sea interaction at the Japan/East Sea (Mooers et al. 2009).

\section{NORMAL UPWELLING DURING SPRING TIDES}

Figure 2 illustrates the agreement between the observed sea level and LZSNFS-produced counterpart at station T from 15 May to 15 June 2007. Being a mixture of diurnal 
(a) ${ }_{118}$
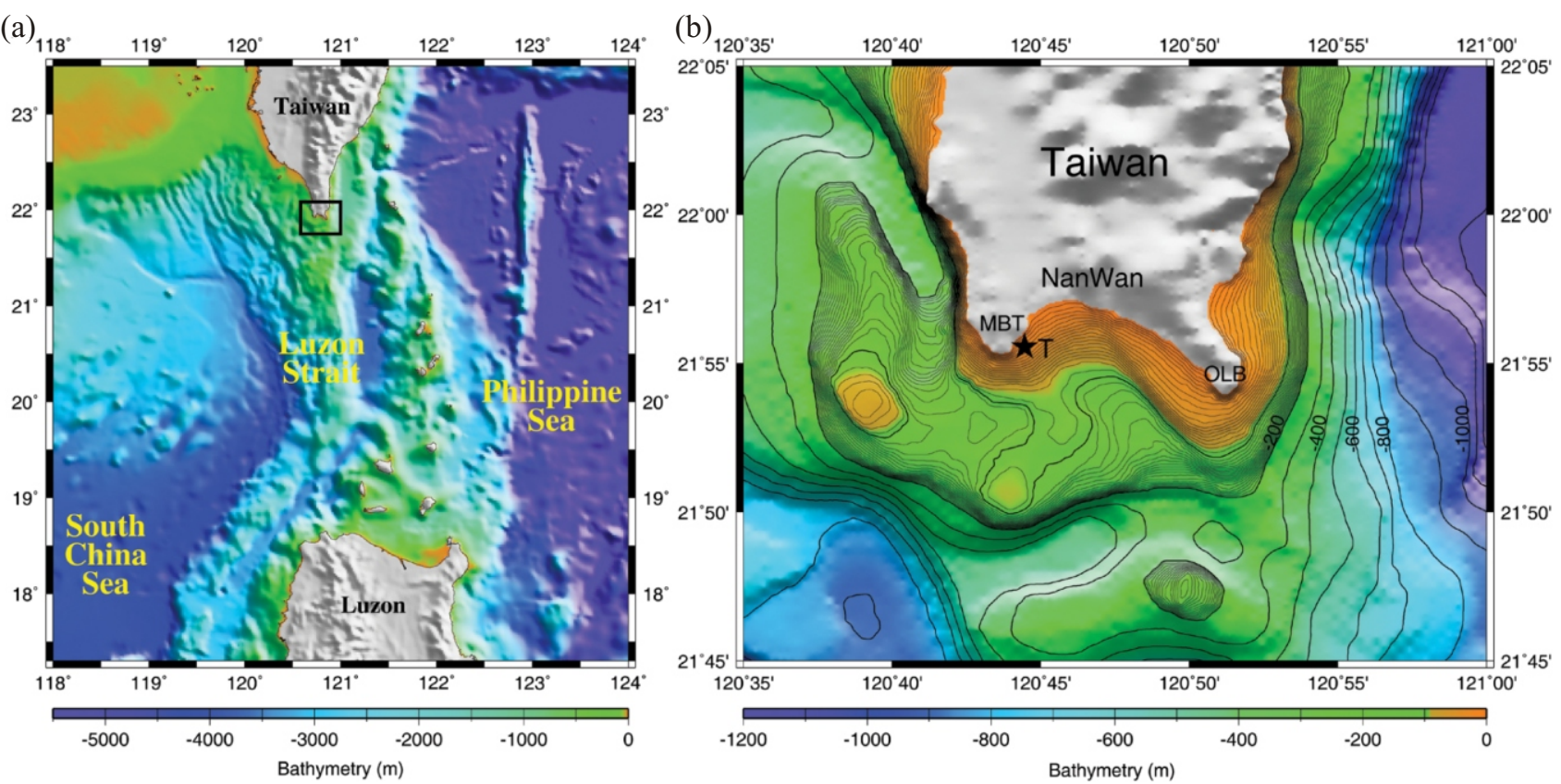

Fig. 1. Bathymetry in the vicinity of (a) Luzon Strait and (b) Nan Wan. Two capes bounding Nan Wan are Mou-Bi-Tou (MBT) and O-Luan-Bi (OLB). Station $\mathrm{T}$ in (b) records bottom water temperature at $7 \mathrm{~m}$ depth and sea level variations.

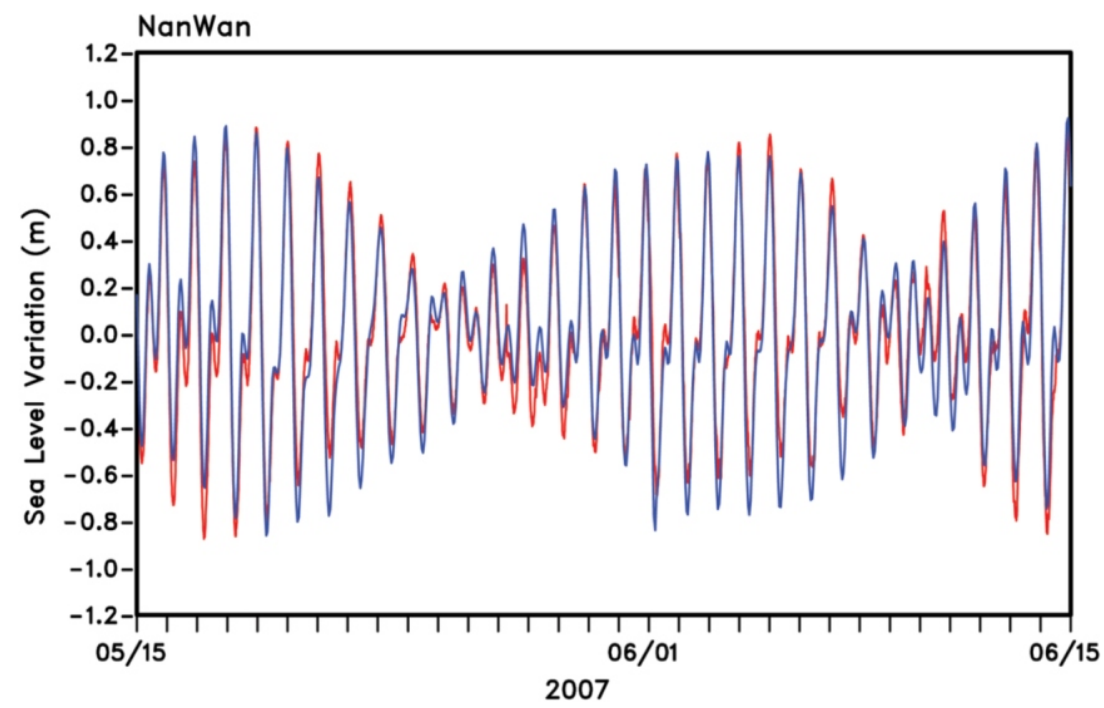

Fig. 2. The observed sea level variation (in red) and model-produced counterpart (in blue) at station T from 15 May to 15 June 2007.

and semidiurnal tides, the sea level variation also contains a pronounced spring-neap cycle. We choose June 2 to illustrate Nan Wan upwelling event during the spring tide. Tidal range in this day exceeds $1.6 \mathrm{~m}$.

Figure 3 shows bihourly currents and temperature at $25 \mathrm{~m}$ depth for 2 June 2007. At hour 0 (GMT), the start of ebb current, upwelling begins to appear southwest of OLuan-Bi. The southward extension ridge from O-Luan-Bi apparently lifts the ebb current to produce the upwelling. It intensifies and expands until hour 8. Upwelling off the tip of Mou-Bi-Tou starts at hour 4, and thereafter intensifies and expands until hour 8 . At hour 10 , as the tidal current recesses, the cold anomaly off Mou-Bi-Tou begins to move to the western coast of Taiwan, while the corresponding anomaly off O-Luan-Bi moves to the central basin of Nan Wan. Both movements are in keeping with the propagation direction of coastal-trapped waves. From hour 10 to hour 14, the two cold anomalies continue to propagate away in the pro- 
pagation direction of coastal-trapped waves. By hour 16, cold-water masses have completely moved out of Nan Wan. The right-bounded movement of the two cold-water masses explains why the temperature drop occurs once daily on the east side of Nan Wan, but twice daily in the west and central parts of the basin (Lee et al. 1999). Leaving Nan Wan upwelling aside, the ebb current also generates a cold cyclonic eddy on the lee (east) side of O-Luan-Bi. It begins to form at hour 4, expands and intensifies until hour 12, and decays slowly thereafter.

In coastal oceans with continuous stratification and variable bottom slope, coastal-trapped waves become a hybrid of internal Kelvin waves, continental shelf waves and topographic Rossby waves (Wang and Mooers 1976). It is difficult to separate them cleanly even if the oceanographic setting is strictly uniform alongshore. The irregular coastline and bathymetry around Nan Wan complicate the setting even further. Nevertheless, further results point to the close resemblance of cold-anomaly propagation to internal Kelvin waves. In the LZSNFS, sizable cold anomalies and their right-bounded propagation show up together during the spring tide but diminish thereafter. The predominance of density forcing associates the right-bounded propagation mostly to internal Kelvin waves, which owe their existence to density anomalies, rather than continental shelf waves or topographic Rossby waves, which arise from the bottom slope. Judging empirically, one can estimate the phase speed from the movement of the cold anomaly that initially appears off Mou-Bi-Tou. From hour 8 to hour 14, the propagation speed is about $45 \mathrm{~km}$ per day or $\sim 0.5 \mathrm{~m} \mathrm{~s}^{-1}$. Ambient currents around Nan Wan, tidal and subtidal alike do not seem able to stop the right-bounded propagation. To the contrary, the right-bounded propagation thrives in the "shadow zone" of the adverse ambient currents. For example, from

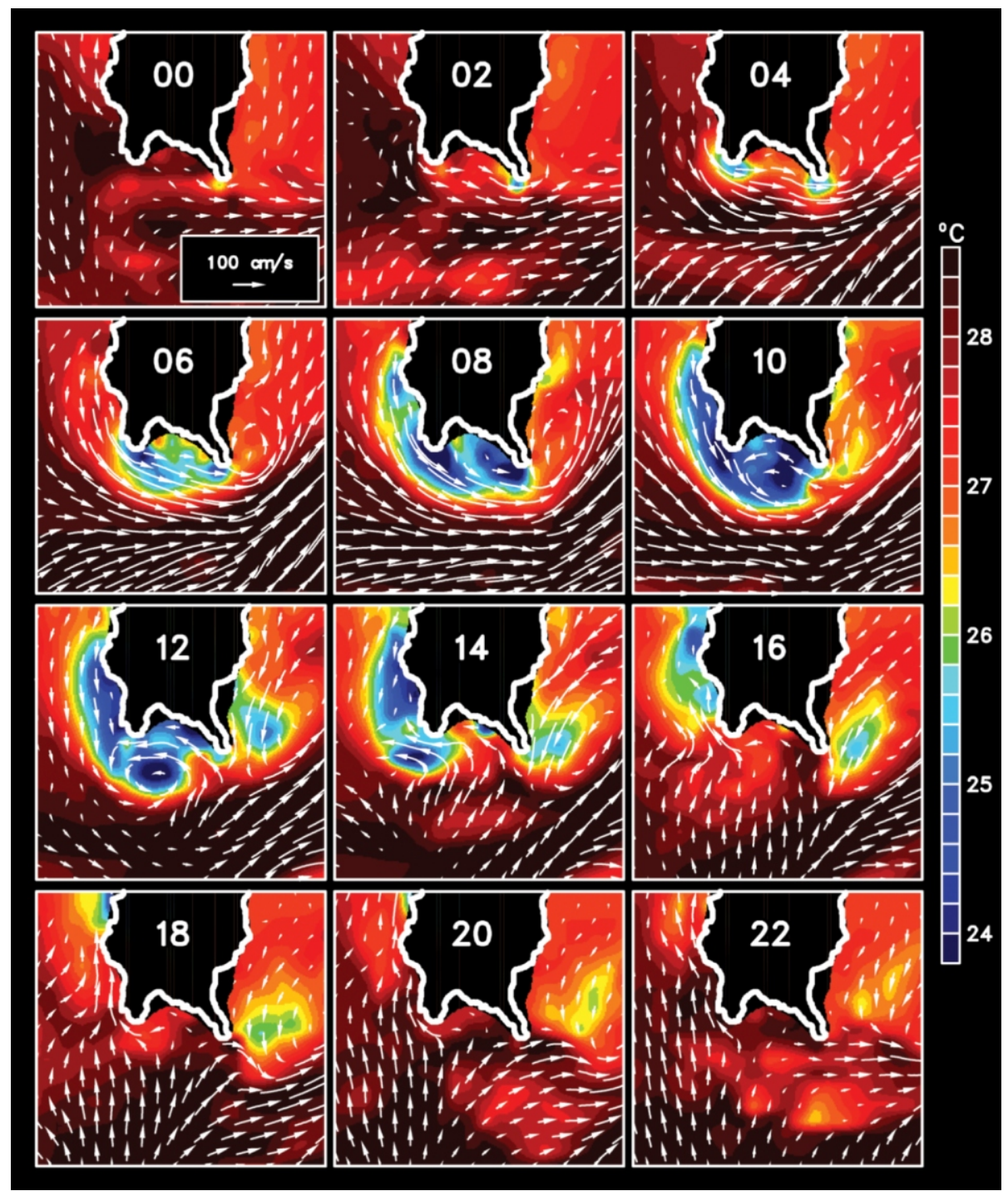

Fig. 3. Bihourly currents and temperature at $25 \mathrm{~m}$ depth for 2 June 2007, showing normal cold-water intrusion during the spring tide. Numbers on land indicate time (GMT) in hours. 
hour 6 to hour 10, the westward expansion of the cold anomaly from O-Luan-Bi is restricted mostly to Nan Wan and its immediate south, where the adverse ambient current is weak or reversed. From hour 12 to hour 16, the rightbounded propagation from Mao-Bi-Tou to the west coast of Taiwan occurs at the expense of diminishing adverse ambient current.

The right-bounded propagation of cold anomalies in Fig. 3 is against the prevailing tidal current from hour 6 to hour 10. Tidal current is therefore not responsible for it. To associate it with the earth's rotational effect, we have terminated the Coriolis force in Fig. 4 after hour 6, the onset of right-bounded propagation. By removing the earth rotation, tidal currents also change gradually in time. Nevertheless, the right-bounded propagation diminishes quickly before the tidal current changes significantly. For example, the tidal current in Fig. 4 (without the earth rotation) essentially re- mains the same as in Fig. 3 (with the earth rotation) from hour 6 to hour 12, but the right-bounded propagation essentially vanishes in Fig. 4 within only six hours after the termination of Coriolis force. This is plausible, because the earth rotation supports the propagation of internal Kelvin waves.

If idealized to the extreme, internal Kelvin waves propagate along a vertical coast and over a flat bottom. With a seaward deepening bottom in the present setting, where is the effective coastal wall and appropriate water depths to support the cold-water propagation in forms similar to an internal Kelvin wave? To examine along this line, we use LZSNFS outputs to compute the daily average of stratification mesh-by-mesh for 2 June 2007, and derive the phase speed and Rossby radius of the first baroclinic mode around Nan Wan from it (Fig. 5). Both quantities increase with the water depth and therefore vary markedly in the area. Nevertheless, relative to the propagation speed along the axial

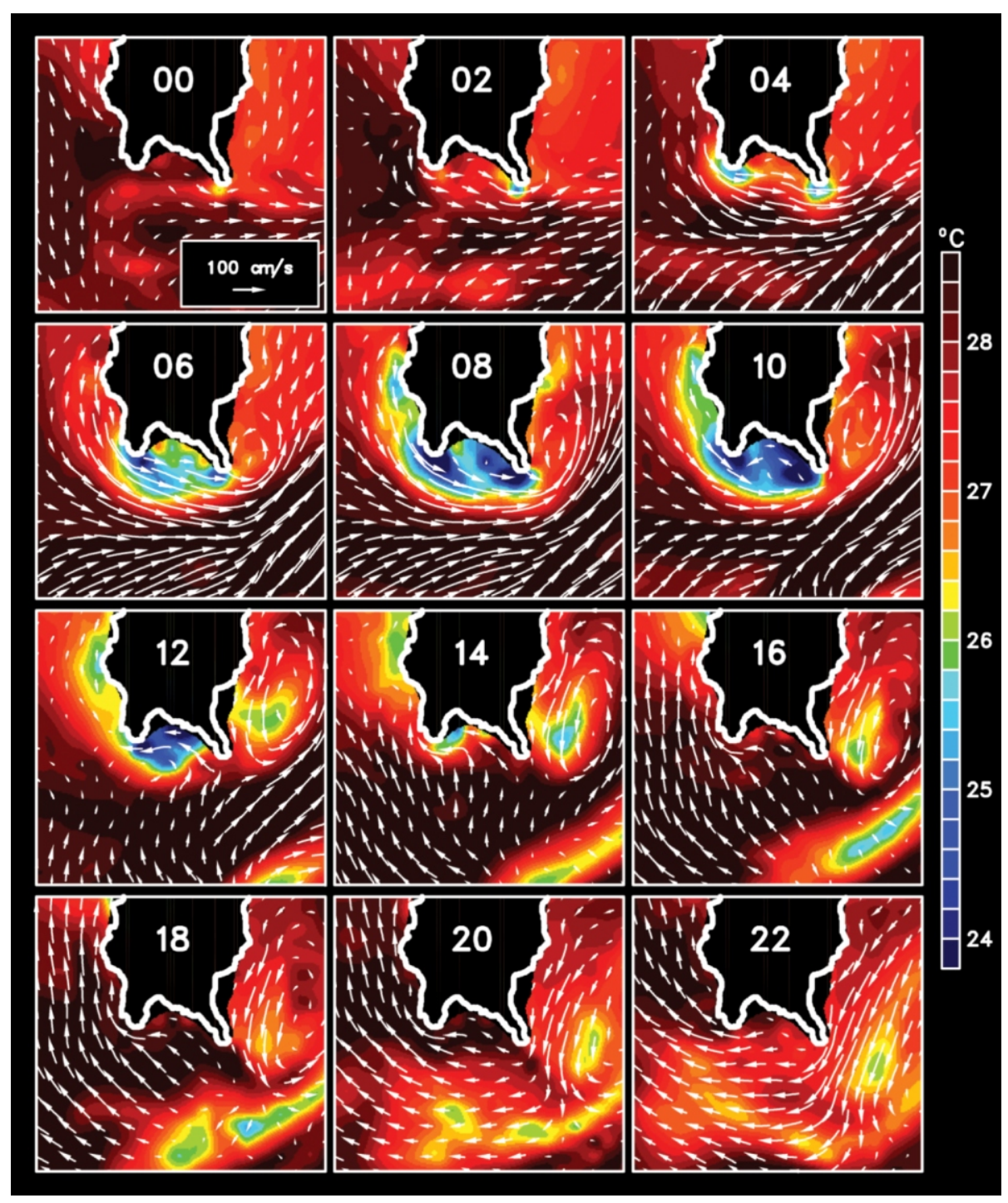

Fig. 4. Same as Fig. 3 except with the removal of Coriolis force after 2 June 2007 at 0600 GMT. 
(a)

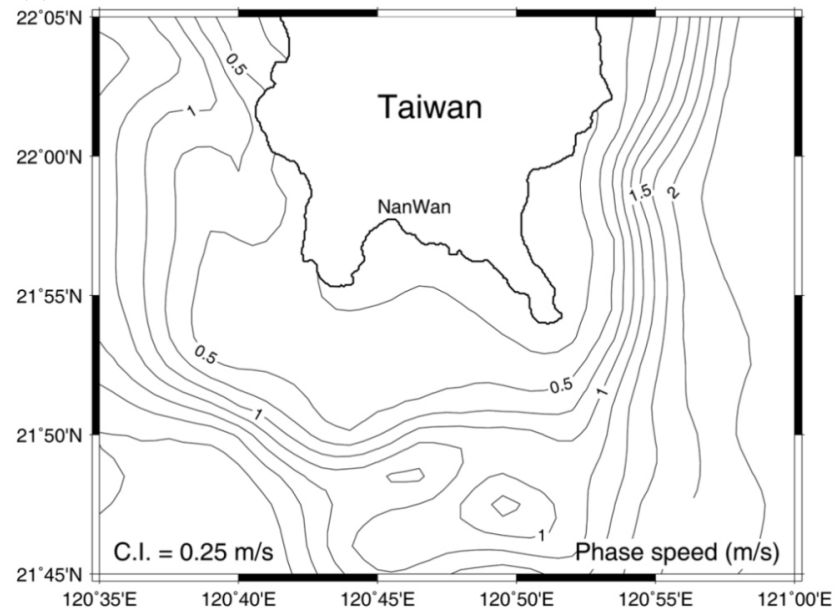

(b)

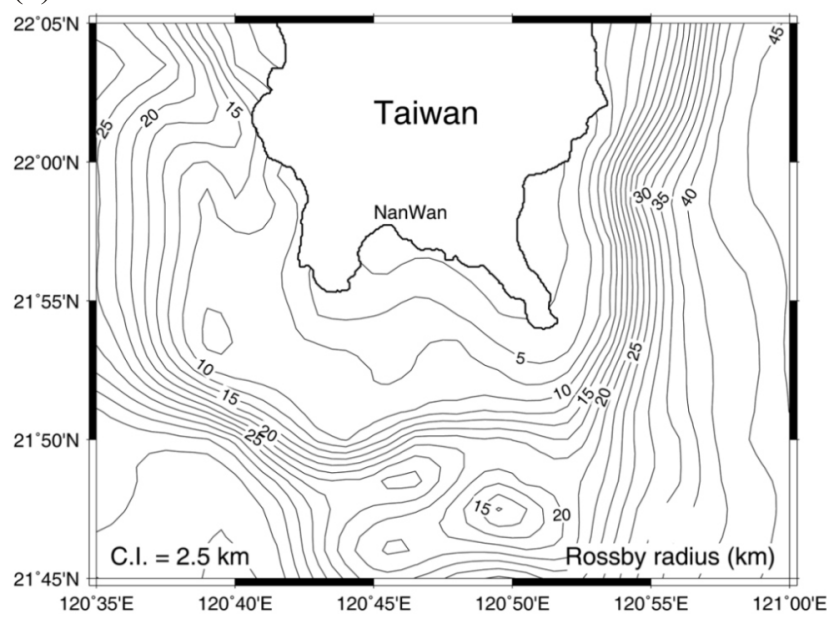

Fig. 5. The phase speed (a) and Rossby radius (b) for the first baroclinic mode around Nan Wan on 2 June 2007.

route of cold anomaly propagation as seen in Fig. 3, Fig. 5 suggests a comparable phase speed of about $0.5 \mathrm{~m} \mathrm{~s}^{-1}$ and a comparable Rossby radius ranging from 5 to $10 \mathrm{~km}$. It is difficult to quantify further beyond this point because, in addition to complexities mentioned above, the oscillating tidal current also modulates the propagation.

For lack of a better term, we use the term "internal Kelvin wave" loosely herein to include also its nonlinear and variable bottom extensions. In theory, the effect of ambient current on the internal Kelvin wave propagation could be nonlinear. Even without the ambient current, nonlinear steepening of internal waves could enhance their propagation speed up to about 10 percent. However, the complex environment around Nan Wan, as we illustrated in Fig. 4, prevents us from isolating the nonlinear effect.

\section{ANOMALOUS UPWELLING IN JULY 2008}

Figure 6a shows the LZSNFS-produced sea level variation (in blue) at station $\mathrm{T}$ from 27 June to 8 July 2008. The observed counterpart (in red), discontinued for service after July 2, is also superimposed to illustrate the agreement. Entering July, the tides begin to enter the spring tidal period. On July 3, for example, the tidal range is about $1.8 \mathrm{~m}$, comparable to the tidal range that produces normal upwelling during spring tides (Fig. 2), but the Nan Wan upwelling, as we demonstrate below, is much stronger.

Figure $6 \mathrm{~b}$ shows the observed bottom temperature at station $\mathrm{T}$ for the same period (in red) and corresponding bottom temperature produced by LZSNFS (in blue). The Nowcast/Forecast System reproduces the timing of each temperature drop rather well. However, the LZSNFS generally underestimates the amplitude of each temperature drop. In particular, after each drop, the temperature often does not rebound to the observed level in LZSNFS. Two reasons can account for the discrepancy. First, station $T$ is less than $1 \mathrm{~km}$ southwest of the thermal discharge from a nuclear power plant. Conceivably, the thermal discharge is able to raise the temperature, but its scale is too small to be included in LZSNFS. Second, the horizontal resolution of LZSNFS $(2.3 \mathrm{~km})$, though fine enough from the modeling point of view, will likely generate horizontal temperature diffusion that is higher than reality, thus reducing the amplitude of temperature drops and rebounds.

Figure 7 shows bihourly currents and temperature at $25 \mathrm{~m}$ depth for 2 July 2008. During the time span, there is a strong subtidal outflow from the northern South China Sea to the Philippine Sea. When superimposed on the tidal current, the ebb current often exceeds $3 \mathrm{~m} \mathrm{~s}^{-1}$. The outflow, tidal plus non-tidal, is strong enough to block the internal Kelvin wave propagation, the natural conduit for the dispersal of cold anomalies. This must be the reason for the larger-thannormal temperature drops.

At hour 2, the southward extension ridge off O-Luan-Bi lifts the eastward flow to produce upwelling. The cold anomaly from O-Luan-Bi intensifies, expands and moves toward the central basin of Nan Wan from hour 2 to hour 6, and dissipates in Nan Wan at hour 8 . The adverse prevailing outflow is apparently too strong to allow this cold anomaly moving to the west coast of Taiwan. At hour 10, the generally westward current from east of O-Luan-Bi generates another sizeable cold anomaly on the lee (west) side of OLuan-Bi. It dissipates in central Nan Wan from hour 10 to hour 18, unable to move to the west side of Taiwan. The cold anomaly generated off Mou-Bi-Tou is even more vulnerable. At hour 4, a small region of cold anomaly first appears to the southeast of Mou-Bi-Tou. It intensifies and expands a little from hour 4 to hour 8 , and dissipates thereafter. In 
general, cold anomalies off both capes fail to disperse following the propagation of internal Kelvin waves during the time span; blocking by the strong subtidal outflow appears to be responsible. Because of the blocking, temperature drops are generally larger than normal. The anomalous upwelling pattern as seen from LZSNFS persists from 1 July to about 5 July 2008. This is the period of alleged hypothermia in the fish population.

Figure 8, similar to Fig. 5, shows the LZSNFS-produced phase speed and Rossby radius of the first baroclinic mode around Nan Wan based on the daily averaged stratification of 2 July 2008. Relative to the normal upwelling condition on 2 June 2007, a slightly stronger stratification on 2 July 2008 increases the phase speed and Rossby radius marginally near Nan Wan. With such a modest phase speed of about $0.5 \mathrm{~m} \mathrm{~s}^{-1}$ just outside the perimeter of Nan Wan, the strong, eastward subtidal flow, as we illustrated in Fig. 7, could easily block the right-bounded propagation of cold anomalies in forms similar to internal Kelvin waves.

\section{SUGGESTED ORIGIN OF ANOMALOUS SUBTIDAL EASTWARD FLOW OFF NAN WAN}

Typhoon Fengshen moved through the northern South China Sea from 22 to 25 June 2008, leading us to suspect it as the main cause of the anomalous subtidal eastward flow off Nan Wan. We now turn to the larger-scale EASNFS, which excludes tides, to examine the effect of this typhoon. Figure 9 contrasts subtidal surface circulation patterns between normal upwelling period (2 June 2007) and anomalous upwelling period (2 July 2008). The difference is more than subtle. For 2 June 2007 (Fig. 9a), the Kuroshio more or less stays away from the South China Sea. This is the typical summerlike pattern, in which the Kuroshio Current stays some distance away from Nan Wan. For 2 July 2008 (Fig. 9c), shortly after the passage of typhoon Fengshen, the Kuroshio Current becomes rather intrusive; the encroachment produces two anticyclonic meanders moving into the northern South China Sea. The northern meander produces strong
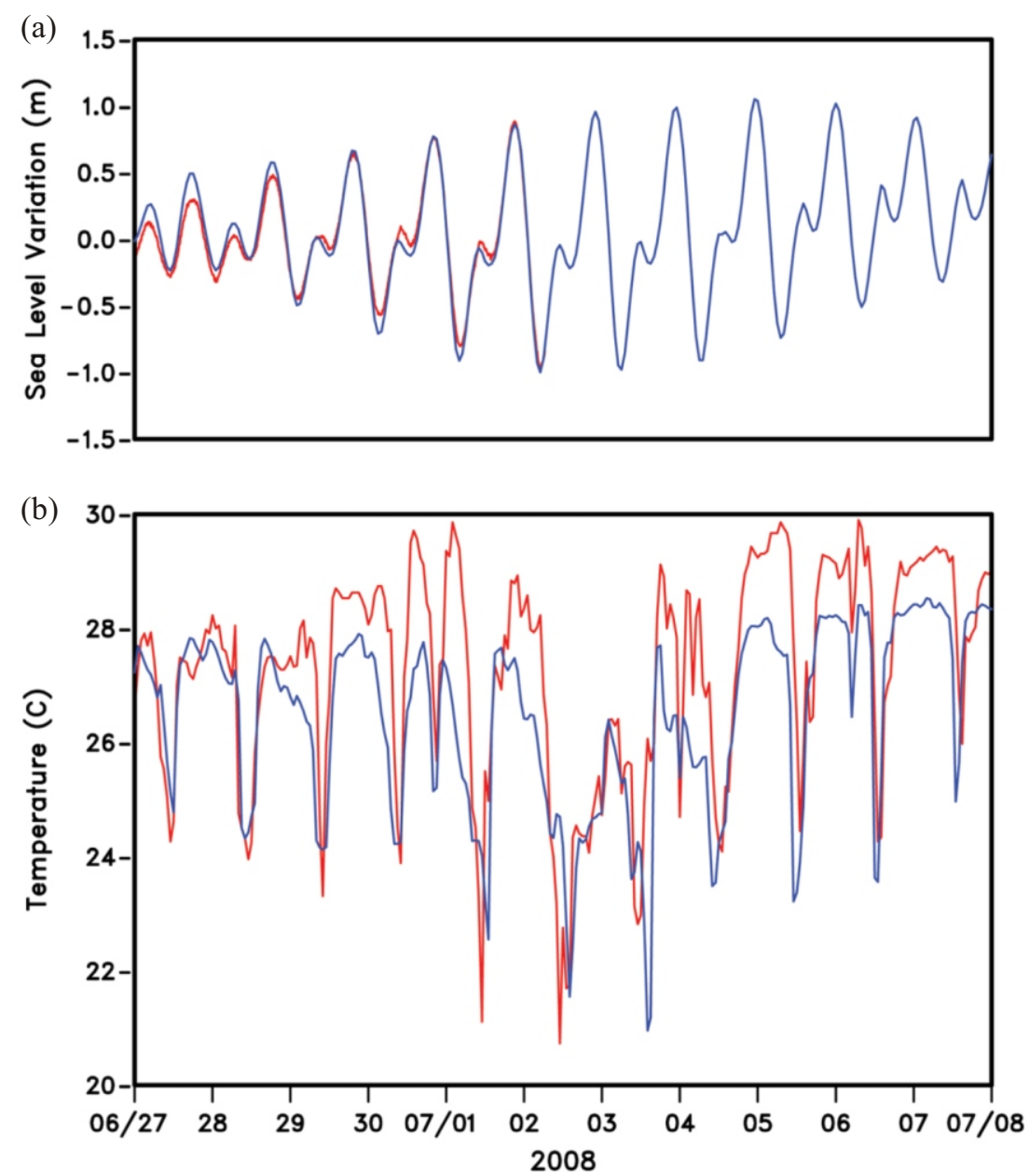

Fig. 6. (a) The observed sea level variation (in red) from 27 June to 2 July 2008 at station T and LZSNFS-produced counterpart (in blue) from 27 June to 8 July 2008. (b) Corresponding time series of bottom temperature from observation (red) and LZSNFS (blue). The time is in GMT, which is 8 hours ahead of local time. 


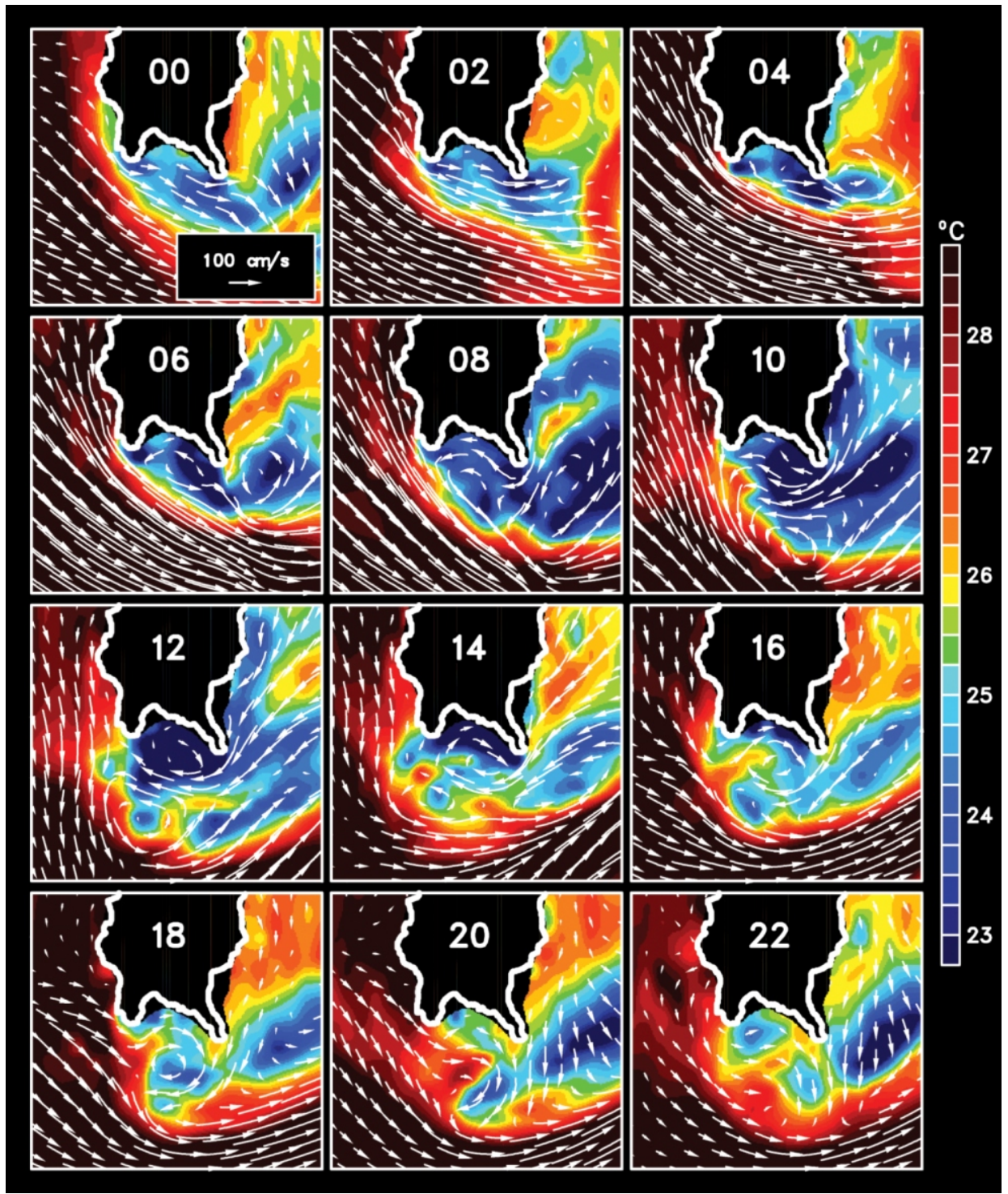

Fig. 7. Same as Fig. 3 except for 2 July 2008.
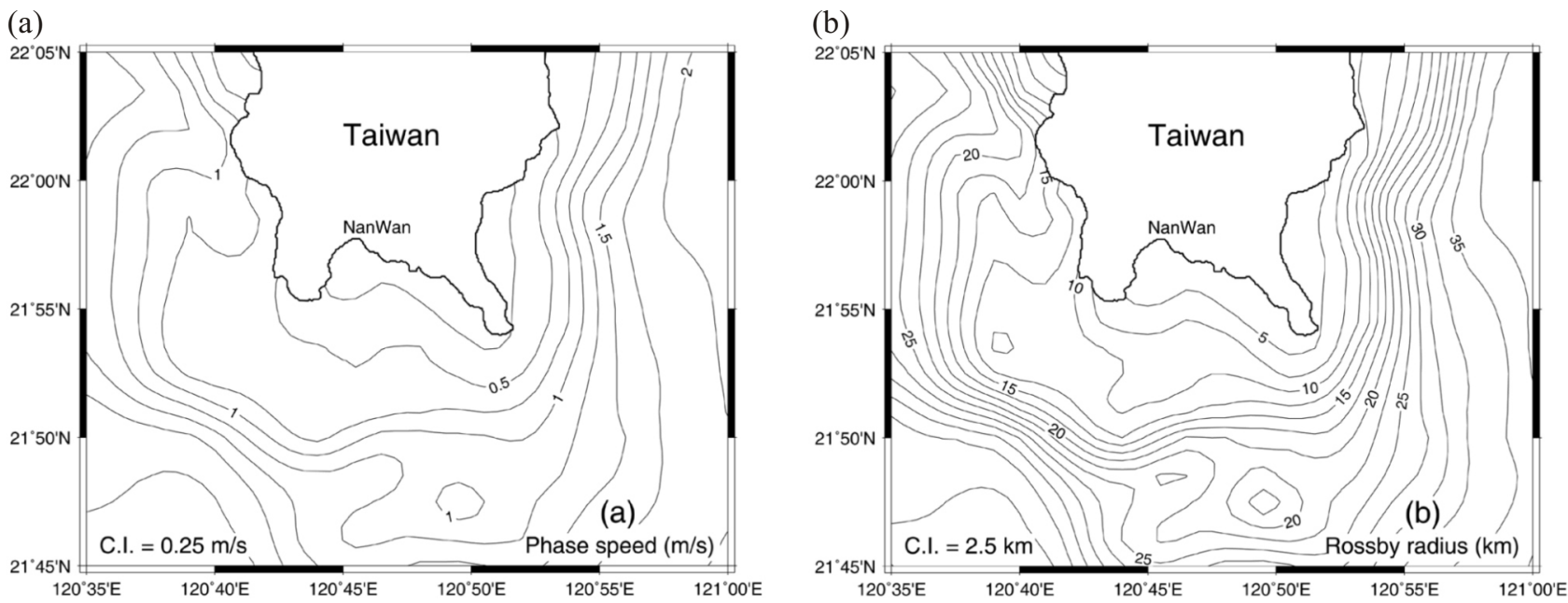

Fig. 8. Same as Fig. 5 except for 2 July 2008. 


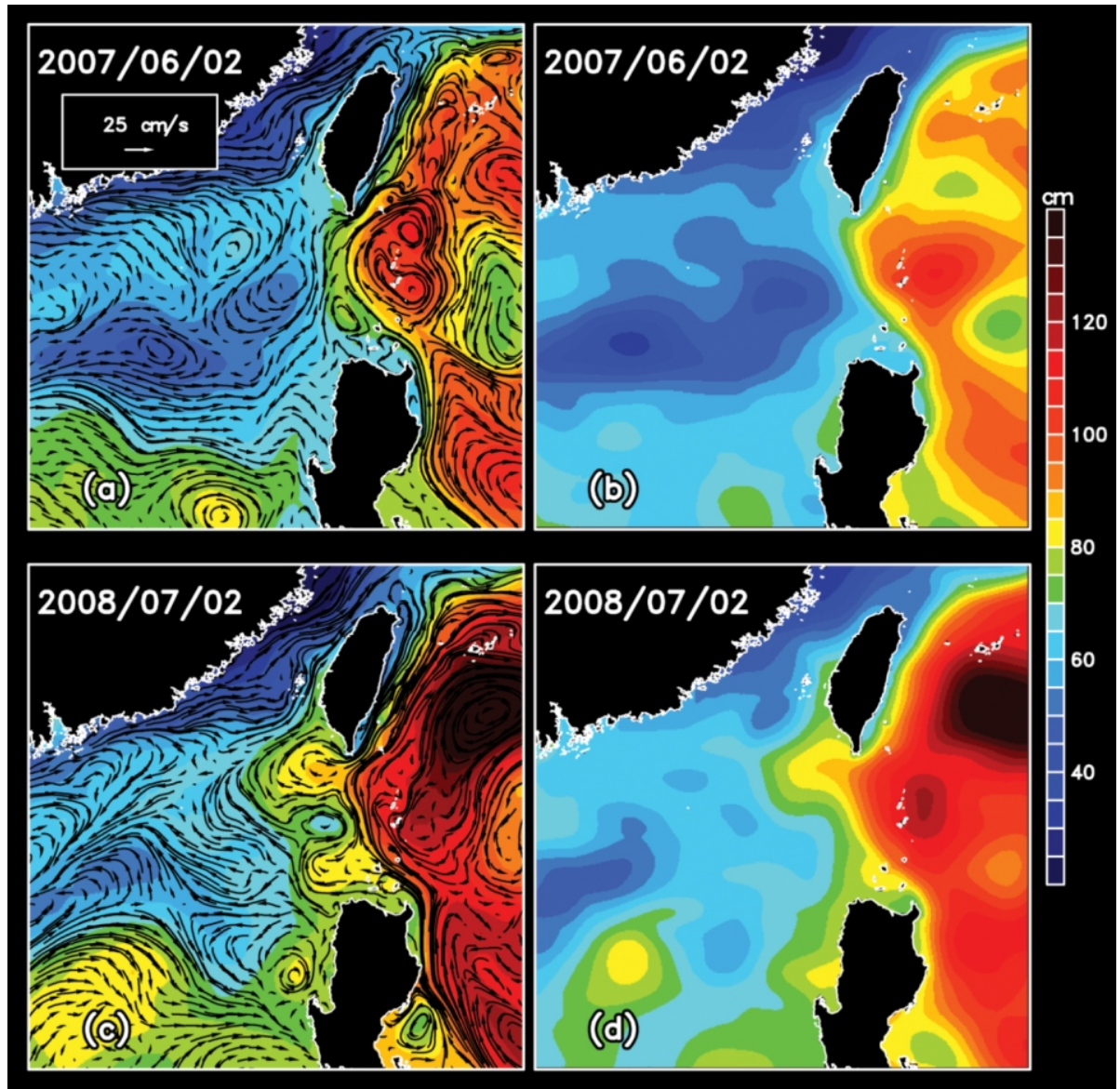

Fig. 9. Subtidal surface circulation and sea surface height (in color) for (a) normal upwelling at 1200 GMT on 2 June 2007 and (c) anomalous upwelling at 1200 GMT on 2 July 2008, produced by the East Asian Seas Nowcast/Forecast System (EASNFS). Panels (b) and (d) show optimal interpolations of corresponding sea surface height fields from all available, contemporaneous altimeter data.

subtidal outflow from the northern South China Sea to the Philippine Sea near Nan Wan.

To the right of Figs. 9a and $\mathrm{c}$ are contemporaneous optimal interpolations of sea surface height fields derived from all available satellite altimeter measurements, including JASON, GFO, and ENVISAT (Jacobs et al. 2002). In particular, this result enters EASNFS through data assimilation, which slowly injects the optimal interpolation into the dynamically active system (Chapman et al. 2004). The similarity between EASNFS-derived and altimeter-derived products emerges as expected because of the data assimilation. The discrepancy is also understandable because of the difference in methodology. Similarities and dissimilarities aside, one also sees anomalous Kuroshio encroachment in July 2008 from the satellite-derived product (Fig. 9d).

The encroaching Kuroshio after Typhoon Fengshen is counterintuitive because it is a distinctively winterlike behavior. Though different in scale, the encroachment is a miniature form of winter intrusion. In winter, the prevailing northeast monsoon moves waters from the northern part to the southern part of the South China Sea. The consequent low sea level anomaly in the northern South China Sea, in turn, invites Kuroshio to intrude (e.g., Chern and Wang 2003). In other words, the low sea level in the northern South China Sea is the required preconditioning for the Kuroshio intrusion in winter. Extrapolating the winter scenario further, did Typhoon Fengshen create a similar but weaker, winter-like low sea level anomaly to invite the Kuroshio encroachment?

Figure 10, again produced by EASNFS, shows selected snapshots of wind stress field, ocean surface currents and sea surface height from 1800 GMT 22 June to 1500 GMT 1 July 2008. Typhoon Fengshen moved rather slowly from Luzon to southern China in three days (from June 22 to 25). A stationary typhoon over the northern South China Sea would propel waters away from its center through surface Ekman transport and generate a sea level depression underneath it. Most of the excess waters should exit the Luzon Strait, the only major deep opening of the South China Sea. Since Fengshen was moving, one expects a delayed response in its wake. A moving typhoon will also generate inertial currents radiating away from its wake with a period of 


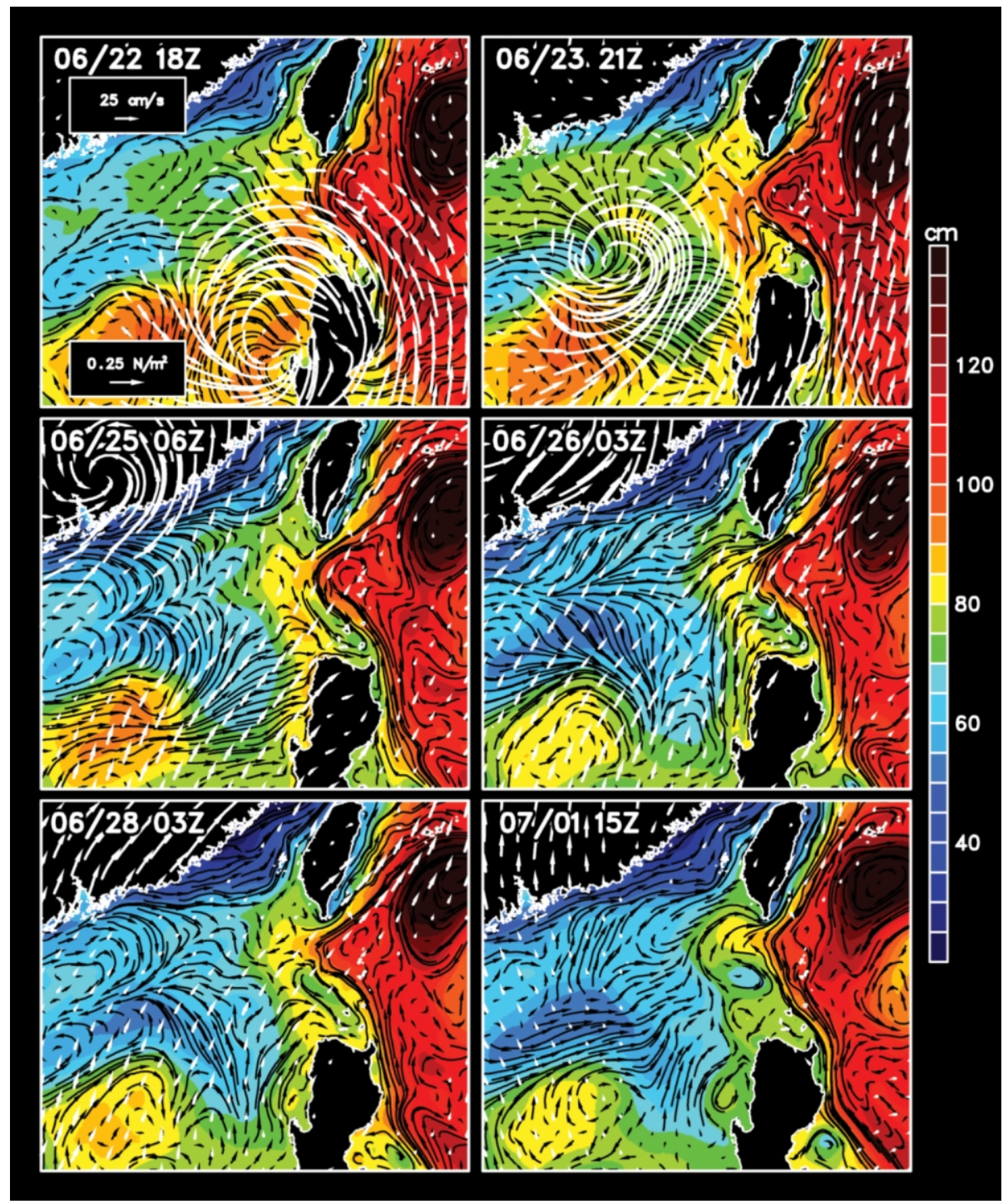

Fig. 10. Time (GMT) evolution of wind stress fields (white arrows), ocean surface currents (black arrows), and the sea surface height during and after the passage of Typhoon Fengshen. Calibration arrows are in the top left panel.

about 35 hours in the northern South China Sea.

Figure 10 clearly shows radiating inertial currents from the wake of Fengshen. Of more relevance to Nan Wan is the strong eastward subtidal flow in its vicinity on June 26 (middle right panel). The eastward flow does not induce strong upwelling in Nan Wan or hypothermia in the fish population, because June 26 is in the middle of neap tide period. After Fengshen landing on southern China, the sea level depression in the northern South China Sea becomes rather extensive, apparently squeezing a substantial amount of surface water away from the South China Sea into the Philippine Sea. The consequent pressure deficit in the northern South China Sea invites Kuroshio encroachment, inducing strong, eastward subtidal flow near Nan Wan on July 1 (bottom right panel). Simply put, the radiating inertial current from the wake of Fengshen first initiated the eastward subtidal flow near Nan Wan, and the Kuroshio encroachment continued it later on.

Obviously, the low sea level anomaly in the northern South China Sea must be close enough to the Kuroshio to induce the Kuroshio encroachment. Figure 11 (left panel), again from EASNFS, shows the zonal distribution of threehourly sea surface height, averaged from $20^{\circ} \mathrm{N}$ to $22^{\circ} \mathrm{N}$, before, during and after Fengshen passage. Fengshen moved through the northern South China Sea from June 23 to 25. Shortly after, the delayed formation of low sea level anomaly expands, with a minor pause in between, to the Luzon Strait $\left(121^{\circ} \mathrm{E}\right)$ on July 1 . Thereafter the Kuroshio, characterized by high sea level, begins to encroach as anticipated.

Figure 11, right panel, shows a concurrent time series of sea surface height anomaly at $21.5^{\circ} \mathrm{N}$ and $120^{\circ} \mathrm{E}$ from 


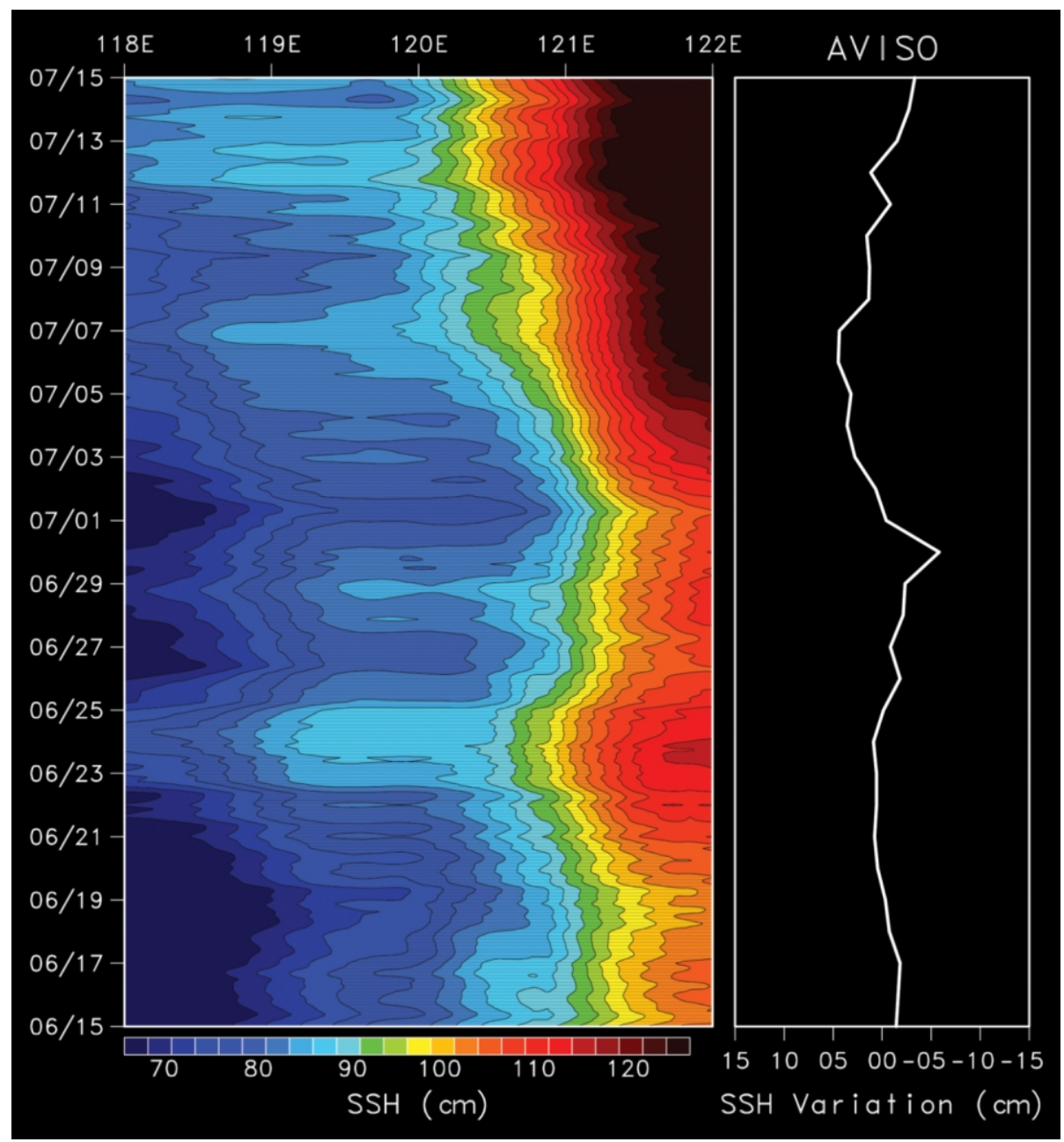

Fig. 11. Zonal distribution of sea surface height (averaged from $20^{\circ} \mathrm{N}$ to $22^{\circ} \mathrm{N}$ ) before, during, and after Fengshen passage, produced by 3 -hourly outputs of EASNFS (left), and satellite-derived sea surface height at $21.5^{\circ} \mathrm{N}$ and $120^{\circ} \mathrm{E}$ from AVISO (right).

AVISO NRT (near real time) product. AVISO derives the sea surface height from near real time altimeter data with algorithms that are completely independent from the treatment of altimeter data in EASNFS. It therefore provides a somewhat independent verification of EASNFS's performance. Specifically, AVISO NRT product blends alongtrack measurements of JASON, ERS-2, Topex-Poseidon, GFO, and EVISAT with an optimal interpolation. At any given time, the optimal interpolation also weighs measurements in a time window that spans from 43 days before to 3 days after. Judging from the result, AVISO seems to overweigh the past and under-weigh the future. In consequence, the Kuroshio encroachment in AVISO occurs approximately one day earlier than in EASNFS. The slight discrepancy, however, does not upset the dynamic process we intend to establish herein.

To quantify further, Fig. 12 shows the 3-hourly volume transport across the entire cross-section of Luzon Strait from 15 June to 10 July 2008, produced by the EASNFS. Also shown is a smoother curve after applying a 2-day low-pass filter. In computing them, the depth average is not ideal because it also contains contributions from greater depths that are not relevant to the Kuroshio encroachment. It nevertheless tells a little more. Leaving high-frequency fluctuations aside, the inflow from the Philippine Sea to the South China Sea generally increases prior to the arrival of Typhoon Fengshen (June 22). After Fengshen impacts fully on the northern South China Sea (June 24), the inflow from the Philippine Sea decreases continuously and eventually becomes an outflow around June 26. Apparently, Fengshen creates a radiating inertial current in its wake and propels northern South China waters out of the Luzon Strait in this time span. The outflow reverses to become a pronounced inflow on June 29; this preconditions the Kuroshio encroachment in response to the low sea level of the northern South China Sea. The inflow reverses back to a weak outflow shortly before July 1 and gradually becomes a modest inflow again thereafter. 


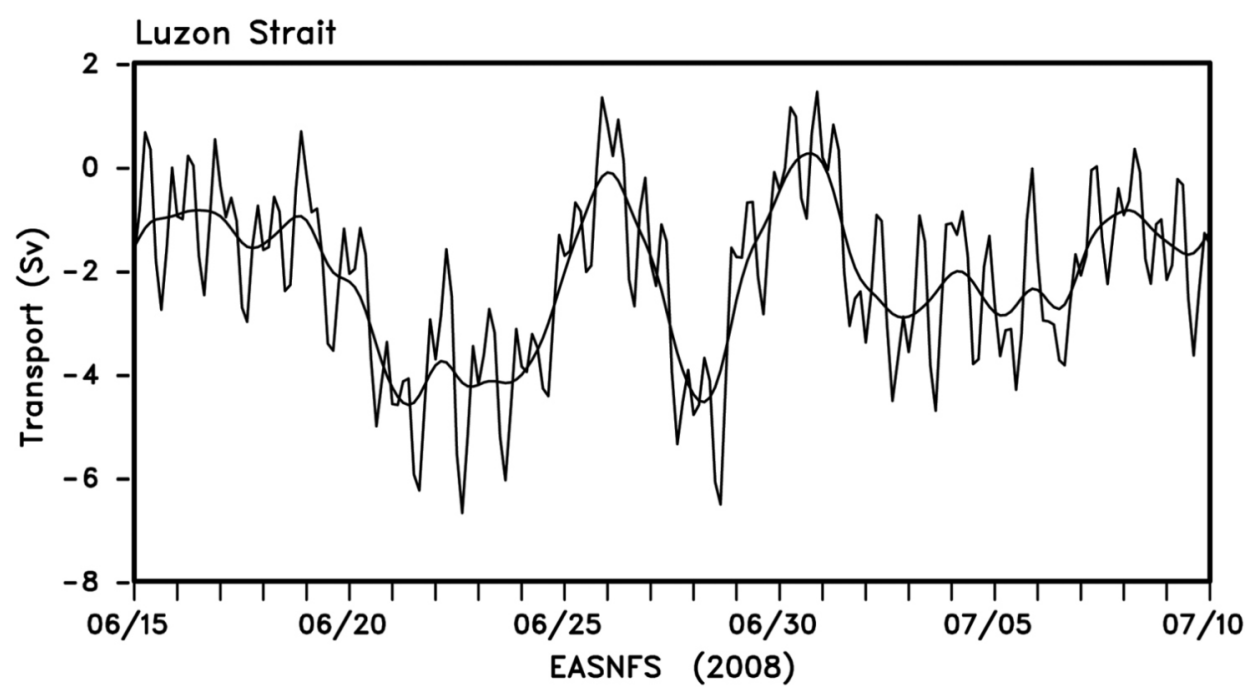

Fig. 12. Three-hourly volume transport across the Luzon Strait $\left(120.8^{\circ} \mathrm{E}\right)$ before, during and after the passage of typhoon Fengshen, produced by East Asian Seas Nowcast/Forecast System (EASNFS). Also shown is the low-frequency response after applying a 2-day low-pass filter. Positive (negative) transports are eastward (westward).

Figure 13 shows power spectrum densities for the Luzon Strait transport. The red spectrum, covering the period from 2008/06/01 00 GMT to 2008/07/18 18 GMT, contains a substantial, relatively quiescent, pre-typhoon time span. Two peaks stand out counterintuitively near diurnal and semidiurnal periods, even though the EASNFS does not simulate tides. The near-diurnal oscillations arise from resonance (quarter-wave seiche) that involves the entire South China Sea (Jan et al. 2007). In the Luzon Strait, the peak-to-peak zonal distance between the two north-south running ridges (Fig. 1a) is about $120 \mathrm{~km}$. It takes about 12 hours for long (non-dispersive) internal waves to travel from one ridge to the other (Chao et al. 2007), producing the near-semidiurnal spectral peak.

Restricting attention to the post-typhoon period, the blue spectrum in Fig. 13 covers the time span from 0000 GMT 2008/06/25 to 1800 GMT 2008/07/09. In addition to the two peaks near diurnal and semidiurnal periods, a third peak near the inertial period ( 35 hours) emerges. The inertial current radiating away from the wake of the typhooncovered area produces these oscillations in the Luzon Strait.

\section{CONCLUSIONS}

Nan Wan upwelling intensifies during the spring tide. Both capes and their southward extension ridges are responsible for the upwelling. Using NRL Luzon Strait Ocean Nowcast/Forecast System, we have identified and contrasted two modes of dispersal for the upwelled cold anomalies. Under normal conditions, cold-water masses propagate away from Nan Wan in forms similar to internal Kelvin waves. Since this is the natural way of dispersion, our results, although limited so far, indicate that the cold anomalies are less likely to over-accumulate in Nan Wan under this normal mode of dispersion. For early July of 2008, the Nowcast/Forecast System suggested the existence

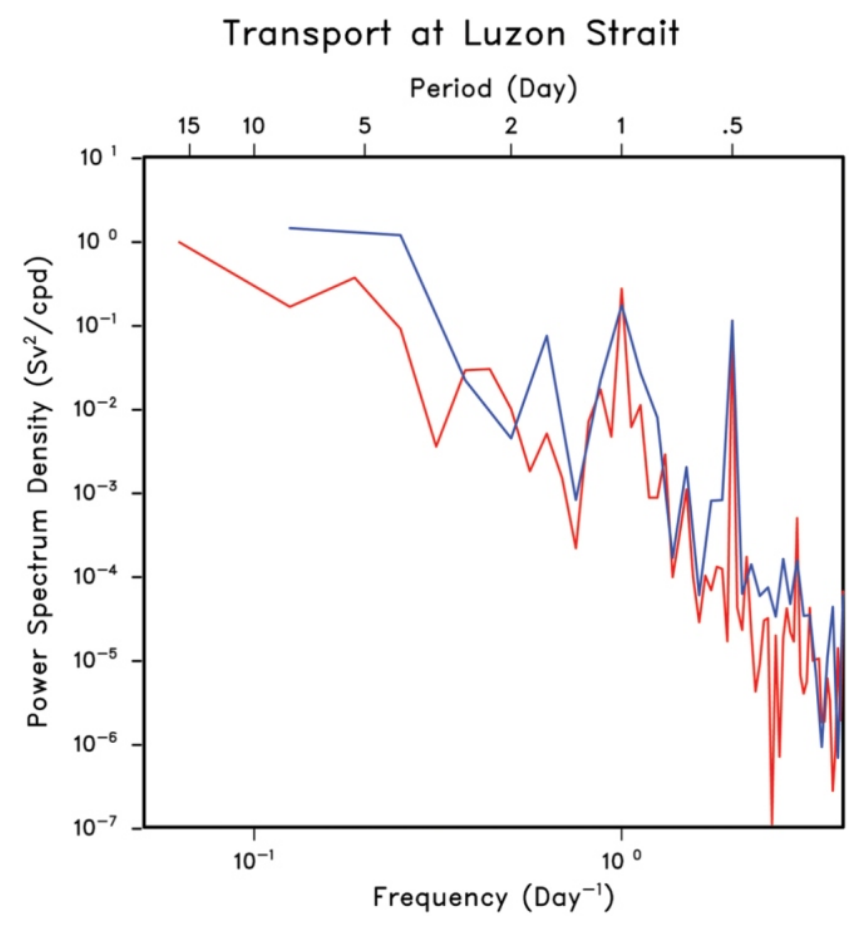

Fig. 13. Power spectrum densities for the 3-hourly Luzon Strait transport. The red line uses a time series from 0000 GMT 2008/06/01 to 1800 GMT 2008/07/18, including a substantial quiescent period before the arrival of Typhoon Fengshen. The blue line uses a shorter, posttyphoon time series from 0000 GMT $2008 / 06 / 25$ to 1800 GMT 2008/07/09, accentuating the post-typhoon inertial oscillations. 
of an anomalous, subtidal and essentially eastward flow near Nan Wan, which, when superimposed on the ebb tide, blocks the cold water dispersion in the propagation direction of internal Kelvin waves. We suggested Typhoon Fengshen as the main cause of the anomalous subtidal flow. Under this anomalous condition, the Nowcast/Forecast System suggested over-accumulation of cold anomalies in Nan Wan. Not surprisingly, the alleged hypothermia in the fish population occurred during this period.

Our results, though a step forward in understanding the Nan Wan upwelling, also open a series of questions waiting for answers. For example, are there still other modes of upwelling in Nan Wan? Will typhoons with substantially different tracks also induce the anomalous upwelling in Nan Wan? During the least observed but extensive Kuroshio intrusion period in winter, is Nan Wan upwelling mostly as anomalous as in July 2008? Our investigations along this line are ongoing.

Acknowledgements DSK is supported by the US Office of Naval Research, code 322 PO under contracts N0001408WX-2-0930 and N00014-08WX-2-1170. SYC is supported by the U.S. Office of Naval Research, code $322 \mathrm{PO}$ under contract N00014-05-1-0279. Taipower Company sponsored the continuous measurement of bottom water temperature and sea level in Nan Wan. This is a NRL contribution JA/7320-08-8258 and an UMCES contribution 4235 .

\section{REFERENCES}

Carnes, M. R., D. N. Fox, R. C. Rhodes, and O. M. Smedstad, 1996: Data assimilation in a North Pacific Ocean monitoring and prediction system. Elsevier Oceanography Series, 61, 319-345. doi: 10.1016/S0422-9894(96)80015-8. [Link]

Centurioni, L. R., P. P. Niiler, and D. K. Lee, 2004: Observations of inflow of Philippine Sea surface water into the South China Sea through the Luzon Strait. J. Phys. Oceanogr., 34, 113-121, doi: 10.1175/1520-0485(2004) 034<0113:OOIOPS >2.0.CO;2. [Link]

Chao, S.-Y., D. S. Ko, R.-C. Lien, and P.-T. Shaw, 2007: Assessing the west ridge of Luzon Strait as an internal wave mediator. J. Oceanogr., 63, 897-911, doi: 10.1007/s10872007-0076-8. [Link]

Chapman, D. C., D. S. Ko, and R. H. Preller, 2004: A high-resolution numerical modeling study of subtidal circulation in the northern South China Sea. IEEE J. Ocean. Eng., 29, 1087-1104, doi: 10.1109/JOE.2004.838334. [Link]

Chen, C. T. A., B. J. Wang, and L. Y. Hsing, 2004: Upwelling and degree of nutrient consumption in Nanwan Bay, southern Taiwan. J. Mar. Sci. Technol., 12, 442-447.

Chern, C. S. and J. Wang, 2003: Numerical study of the upperlayer circulation in the South China Sea. J. Oceanogr., 59, 11-24, doi: 10.1023/A:1022899920215. [Link]

Fox, D. N., W. J. Teague, C. N. Barron, and M. R. Carnes, 2002:
The Modular Ocean Data Assimilation System (MODAS). J. Atmos. Ocean. Technol., 19, 240-252, doi: 10.1175/ 1520-0426(2002)019<0240:TMODAS > 2.0.CO;2, [Link]

Jacobs, G. A., C. N. Barron, D. N. Fox, K. B. Whitmer, S. Klingenberger, D. May, and J. P. Blaha, 2002: Operational altimetry sea level products. Oceanography, 15, 12-21.

Jan, S., C. S. Chern, J. Wang, and S. Y. Chao, 2007: Generation of diurnal $\mathrm{K}_{1}$ internal tide in the Luzon Strait and its influence on surface tide in the South China Sea. J. Geophys. Res., 112, C06019, doi: 10.1029/2006JC004003. [Link]

Keen, T. R., D. S. Ko, R. L. Slingerl, and S. Riedlinger, 2006: Potential transport pathways of terrigenous material in the Gulf of Papua. Geophys. Res. Lett., 33, L04608, doi: 10.1029/2005GL025416. [Link]

Ko, D. S., P. J. Martin, C. D. Rowley, and R. H. Preller, 2008: A real-time coastal ocean prediction experiment for MREA04. J. Mar. Syst., 69, 17-28, doi: 10.1016/j.jmarsys.2007.02. 022. [Link]

Lee, H. J., S. Y. Chao, K. L. Fan, Y. H. Wang, and N. K. Liang, 1997: Tidally induced upwelling in a semi-enclosed basin: Nan Wan Bay. J. Oceanogr., 53, 467-480.

Lee, H. J., S. Y. Chao, K. L. Fan, and T. Y. Kuo, 1999: Tideinduced eddies and upwelling in a semi-enclosed basin: Nan Wan. Estuarine. Cont. Shelf Res., 49, 775-787, doi: 10.1006/ecss.1999.0524. [Link]

Liang, W. D., Y. J. Yang, T. Y. Tang, and W. S. Chuang, 2008: Kuroshio in the Luzon Strait. J. Geophys. Res., 113, C08048, doi: 10.1029/2007JC004609. [Link]

Lin, I. I., C. C. Wu, I. F. Pun, and D. S. Ko, 2008: Upper-ocean thermal structure and the western North Pacific category 5 typhoons. Part I: Ocean features and the category 5 typhoons' intensification. Mon. Wea. Rev., 136, 3288-3306, doi: 10.1175/2008MWR2277.1. [Link]

Mooers, C. N. K., H. S. Kang, and D. S. Ko, 2009: The response of the JES to synoptic scale atmospheric forcing as estimated by EASNFS. J. Mar. Syst., submitted.

Rhodes, R. C., H. E. Hurlburt, A. J. Wallcraft, C. N. Barron, P. J. Martin, O. M. Smedstad, S. Cross, E. J. Metzger, J. Shriver, A. Kara, and D. S. Ko, 2002: Navy real-time global modeling system. Oceanography, 15, 29-43.

Su, J. C., T. C. Hung, Y. M. Chiang, T. H. Tan, K. H. Chang, K. T. Shao, P. P. Hwang, K. T. Lee, C. C. Huang, C. Y. Huang, K. L. Fan, and S. Y. Yeh, 1989: An ecological survey on the waters adjacent to the nuclear power plant in southern Taiwan. Special publication No. 70, National Scientific Committee on Problems of the Environment, Academia Sinica, Taipei, Taiwan, ROC, 238 pp.

Teague, W. J., D. S. Ko, G. A. Jacobs, H. T. Perkins, J. W. Book, S. R. Smith, K. I. Chang, M. S. Suk, K. Kim, S. J. Lyu, and T. Y. Tang, 2006: Currents across the Korea/Tsushima Strait: Review of LINKS observations. Oceanography, 19, 52-65.

Wang, D. P. and C. N. K. Mooers, 1976: Coastal-trapped waves in a continuously stratified ocean. J. Phys. Oceanogr., 6, 853-863, doi: 10.1175/1520-0485(1976)006<0853: 
CTWIAC $>2.0 . \mathrm{CO} ; 2$. [Link]

Wu, C. R. and T. L. Chiang, 2007: Mesoscale eddies in the northern South China Sea. Deep-Sea Res. II, 54, 15751588, doi: 10.1016/j.dsr2.2007.05.008. [Link] 